\title{
Torsion of epiploic appendages simulating acute appendicitis
}

\author{
Peer Zada Mohd Irfan ${ }^{*}$, Neeraj Koul'², Surbhi Abrol ${ }^{3}$, R.K. Chrungoo ${ }^{4}$ \\ ${ }^{1}$ Senior Resident, ${ }^{2}$ Associate Professor, ${ }^{3}$ Post Graduate III ${ }^{\text {rd }}$ Year, ${ }^{4}$ Professor and Head Unit, ${ }^{1-4}$ Dept. of Surgery, Acharya \\ Shri Chander College of Medical Sciences and Hospital, Jammu, Jammu and Kashmir, India
}

*Corresponding Author: Peer Zada Mohd Irfan

Email: irfanpeer19711@gmail.com

\begin{abstract}
Torsion of epiploic appendages is rare clinical condition which can mimic acute abdomen such as acute appendicitis, acute cholecystitis, diverticulitis or other cause of acute abdomen depending upon the location of torsion of appendage and degree of ischaemia. They pose a real clinical challenge to diagnose. We report three such cases who presented to us with acute pain in abdomen. Epiploic appendagitis often eludes the diagnosis preoperatively.
\end{abstract}

Keywords: Epiploic appendages, Acute appendicitis, Gangrene, Diagnostic laparoscopy.

\section{Introduction}

Epiploic appendages also called as appendices epiploicae, they are fatty appendages about $0.5-5 \mathrm{~cm}$ in length, arranged in two rows along the serosa of colon from caecum to rectosigmoid junction. A normal adult human being usually has about $50-100$ appendices epiploicae. They are attached to colonic surface by vascular stalk which consists of one to two arterioles and usually drained by single venule. ${ }^{1}$ The cecum and the sigmoid colon are the predominant physiological sites of appendageal occurrence. The epiploic appendages undergo torsion, the exact cause is unknown. It may develop because of sudden rotation of the body, or it may be due to a long pedicle, or the vein may be longer, or it may be caused by excess fat in the pedicles.

\section{Case Report 1}

A 28 years old female patient presented in the emergency with acute onset severe pain in right iliac fossa (RIF). She had no nausea or vomiting and no genitourinary symptom. Appetite and bowel functions were normal. On clinical examination temperature was $98.4^{\circ} \mathrm{F}$, guarding and tenderness was present in RIF. Total leucocyte counts (TLC) $7500 / \mathrm{mm}^{3}$, C-reactive protein (CRP) $4.3 \mathrm{mg} / \mathrm{dl}$. Ultrasonography (USG) and Computed tomography (CT) scan were inconclusive. Diagnostic laparoscopy was done, and a tortuous and gangrenous appendage was found attached to the caecum and was excised. Histopathological examination (HPE) revealed infarcted adipose tissue with fat necrosis (Fig. 1). Post-operatively after 6 hours patient was started on orals and discharged next day. On follow up there was no fresh complaint.

\section{Case Report 2}

A 45 years old female patient presented in the emergency with acute onset pain in RIF, severe in intensity and non-radiating. She had nausea but no vomiting. Appetite and bowel functions were normal. On clinical examination there was tenderness in the RIF. Temperature 98.6F, TLC $9000 / \mathrm{mm}^{3}$, CRP 4.6 $\mathrm{mg} / \mathrm{dl}$. USG and CT-scan abdomen were in conclusive. Patient was taken for diagnostic laparoscopy; small gangrenous appendage was found attached to the ascending colon and was excised. HPE revealed peripheral fat necrosis (Fig. 2). Post-operatively period was uneventful, and the patient was discharged on day 1 postoperatively. On follow up after there was no fresh complaint.

\section{Case Report 3}

A 62 years male patient presented in the emergency with pain right upper quadrant, mild to moderate in intensity non radiating. He had no nausea or vomiting. Appetite and bowel functions were normal. On clinical examination there was guarding and tenderness present. Temperature $99 \mathrm{~F}$, TLC $8400 / \mathrm{mm}^{3}$, CRP $5.2 \mathrm{mg} / \mathrm{dl}$. USG abdomen showed hyperechoic pericolic, noncompressible mass. CT-scan of abdomen was suggestive of appendagitis epiploicae in right subhepatic location $4 \mathrm{~cm}$ from right lobe of liver (Fig. 3). Patient was taken for laparoscopic excision of the appendage. Post-operative period was uneventful, and the patient was discharged in day 1. On regular follow up there was no fresh complaint. 


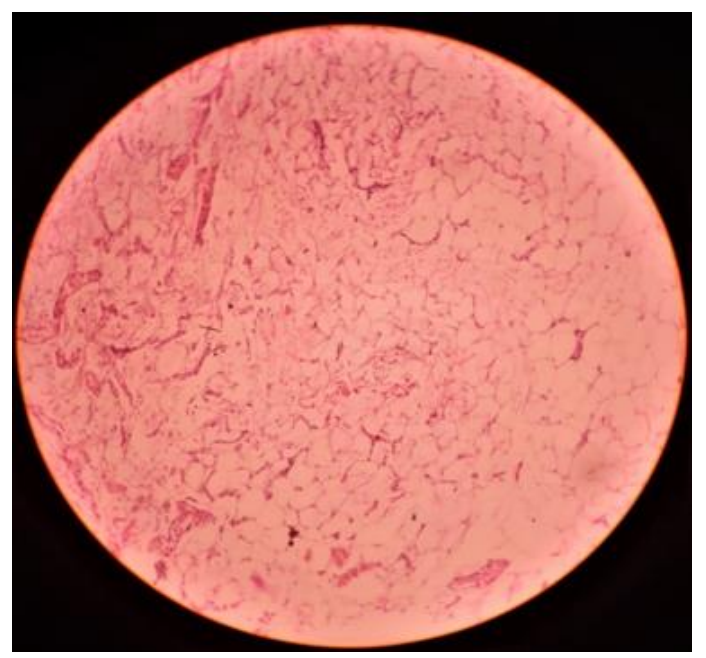

Fig. 1: Shows adipose tissue infraction with fat necrosis

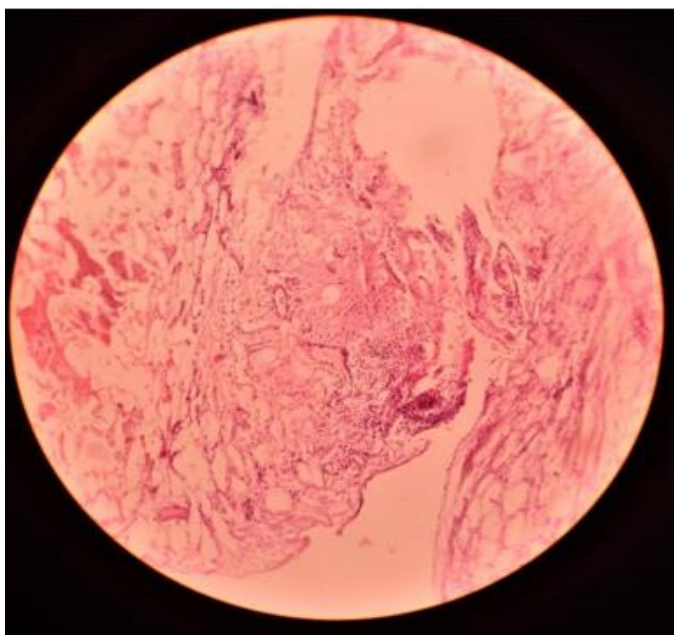

Fig. 2: Shows peripheral fat necrosis

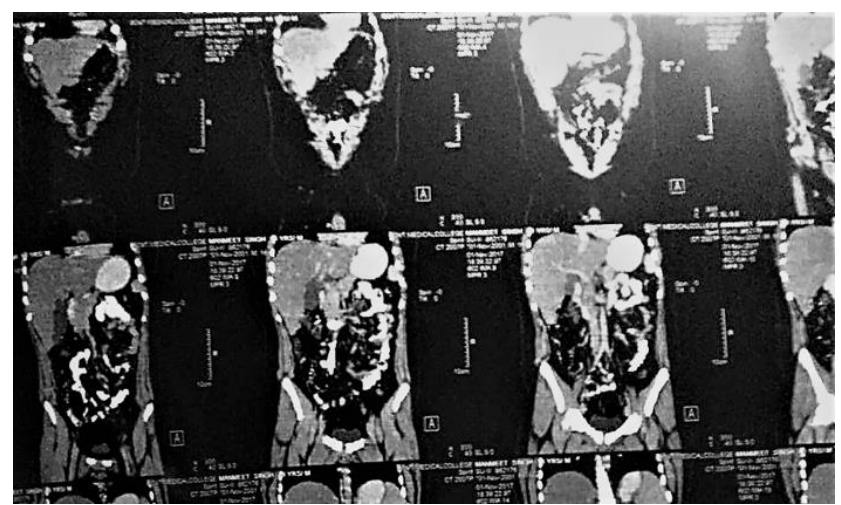

Fig. 3: CT- scan of abdomen showing swollen appendage in the subhepatic region.

\section{Discussion}

Epiploicae appendagitis is rare cause of acute abdominal pain from the clinical spectrum of the disease it is very difficult to diagnose the patients. The patients usually present with localized pain, which is the most common symptom, depending upon the location of involved appendage. It can occur at any age and there is no sex predilection. Appetite and bowel functions are not affected. Abdominal tenderness and sometimes guarding is present. CRP is mildly elevated, and rest of laboratory investigations are usually within normal limits. USG shows hyperechoic noncompressible pericolic mass, ${ }^{2}$ with lack of blood flow on colour doppler. ${ }^{3}$ The definitive diagnosis can be made on CTscan of abdomen hyper-attenuated ring with adjacent fat stranding or a lobulated fatty mass. ${ }^{4}$ The preoperative diagnosis of appendagitis remains difficult and needs the high clinical suspicion. The differential diagnosis of appendagitis includes acute appendicitis, diverticulitis, torsion of ovarian cyst, haemorrhagic ovarian cyst, mesenteric lymphadenitis acute cholecystitis, omental infaraction, ${ }^{5}$ depending upon the site of involved appendage. ${ }^{6}$

The treatment of torsion of epiploicae appendages remains excision that can be done laparoscopically or open technique, but the laparoscopic procedure is highly appealing to the patient and surgeon also. Conservative management has also been proposed in the literature but is associated with $40 \%$ recurrence of symptoms $^{7}$. If the diagnosis is missed the epiploicae appendagitis can lead to the complications like adhesions, abscess formation, bowel obstruction.

\section{Conclusion}

Epiploic appendagitis is an acute abdominal surgical condition which often eludes the diagnosis preoperatively. In patients with localized, sharp, acute abdominal pain which is not associated with any other severe symptom like vomiting, fever or typical abdominal laboratory values, diagnosis of epiploicae appendagitis should be considered. With the increase of primary abdominal USG and CT scans, which have become standard diagnostic tools for acute abdomen, epiploicae appendagitis will be more frequently diagnosed. Diagnostic laparoscopy should be done in patients in which USG and CT- scan abdomen are inconclusive.

\section{Source of Funding \\ None.}

\section{Conflict of Interest}

None.

\section{References}

1. Li A, Lau S, Loke TKL, Chan JCS. Primary epiploic appendagitis. HK Coll Radiol 2004;7:81-83. 
2. Danse EM, Van Beers BE, Baudrez V, Pauls C, Baudrez Y, Kartheus A, et al. Epiploic appendagitis: Color Doppler sonographic findings. Eur Radiol 2001;11:183-6.

3. Hasbahceci M, Erol C, Seker M. Epiploic appendagitis: is there need for surgery to confirm diagnosis in spite of clinical and radiological findings. World J Surg 2012;36:441-6.

4. Barbier C, Denny P, Pradoura JM, Bui P, Rieger A, Bazin A, et al. Primary Epiploic Appendagitis: US, CT and MR Findings. J Radiol 1998;79:14791485.

5. Mcclure MJ, Khalili K, Sarrazin J. Radiological features of epiploic appendagitis and segmental omental infarction. Clin Radiol 2001;56:819-27
6. Shrestha B, Hampton J. Recurrent epiploic appendagitis and peritoneal dialysis: A case report and literature review. World J Nephrol 20143(3):114-7.

7. Schnedl WJ, Krause R, Wallner-Liebmann SJ, Tafeit E, Mangge H, Tillich M et al. Primary epiploic appendagitis and successful outpatient management. Med Sci Monit. 2012;18:CS48-CS51.

How cite: Irfan PZM, Koul N, Abrol S, Chrungoo RK. Torsion of epiploic appendages simulating acute appendicitis. IP J Surg Allied Sci 2020;2(2):41-3. 